Orlando J. Gens

\title{
LENGuAje, POESÍA Y MITO
}

Las nociones de cultura ('civilización', 'primitivismo' o 'salvajismo' incluidas), de ciencia y técnica enfrentadas a las de arte ('poesía' mediante), y a la de religión ('mito', 'magia', 'hechiceria' entremezcladas) inquietaron a los hombres de todos los tiempos civilizados. El enfurecimiento del logos las arrastro, en su afán definitorio y taxonómico, a una confusión muchas veces dramática: el fanatismo y la intolerancia se encargaron de consumarla, pese a los esfuerzos bien intencionados de la psicología profunda, las artes plásticas y poéticas, la etnologia, la semántica, la epistemología y la filosofía. Confusión y desasosiego que se trastornaron aún más con la consecuente $e$ intrincadísima teoría de los símbolos, con todas sus derivaciones lucubrativas. Como remate, una prolffica, aunque impar, bibliografía vino a solidificar este entramado más racional que afecto - volitivo. Menudearon las simbologias de las ciencias, de las artes plásticas, de la música, de la poesía, de la religión, del mito. Pero, para alivio de tan desmesurado enredo, hubo de sobrevenir la puntualidad metódica y el enriquecimiento gnoseológicos de tales conflictivas nociones.

De hecho, a la naturaleza de este artículo habrán de interesar sobremanera aquellas que giran en torno del lenguaje, de la poesía y del mito, actualizadas al trasluz de las modernas corrientes estructuralistas y justificadas en el complejisimo proceso de la comunicación y entendimiento humanos.

2

En el mismo punto de partida nomás se tropieza con la primera complicación: el término mito, en la clásica y erudita lengua griega, of recia una curiosa diversidad conceptual, de tal modo que alcanzaba a nutrirse de la savia semántica de las 
otras dos voces: lenguaje y poesía. Un conocido diccionario de griego-español apunta las siguientes acepciones: "palabra, dicho"; "discurso páblico"; "conversación, discusion"; "narración, noticia"; "fábula, narración fabulosa, leyenda, cuento". Ojos poco avizores pueden atisbar al instante las correspondencias pertinentes: "palabras, discursos, conversaciones" constituyen la concreción más elemental del lenguaje humano; "fábulas, narraciones fabulosas, leyendas, cuentos" son, desde siempre, numen acicateante de los poetas; y la "poesía" continúa siendo el modus operandi más linajudo del lenguaje humano. Sin embargo, aparecen nítidas las diferencias en cuanto se formaliza cada una de las tres áreas. Una inteligencia mucho más perspicaz, como la de Bronislaw Malinowski por ejemplo, puede distinguir el mito de las otras formas narrativas: "Los cuentos populares sirven de entretenimiento; las leyendas satisfacen ambiciones sociales y los mitos son mirados no sólo como verdaderos, sino también como venerables y sagrados, desempeñando un papel cultural muy importante" (1). Aunque estas observaciones fueron formuladas por Malinowski a partir del testimonio de pueblos primitivos o salvajes, bien valen como punta de lanza discriminatoria de realidades que, si no son del todo antagónicas, funcionan como experiencias antropomórficas diferenciadas que conviene esclarecer con cautela.

Comencemos por el lenguaje. Sabido es que, desde Platón hasta los altimos teóricos del lenguaje, hay coincidencia plena en reconocerle su eficacia como el instrumento más competente para la comunicacion entre los hombres y, sobre todo, en desentrañarle su naturaleza biplánica (significante/significado; contenido/expresión). Lingüistas, antropర́logos, sociólogos o etnólogos contemporáneos le especifican, casi exhaustivamente, sus funciones primarias (referencial, metalingüistica, emotiva, poética, conativa y fática); sus niveles socioculturales (general/ regional, formal/informal, culto/vulgar, cientifico/jergal, urbano/ rural, etc.); sus manifestaciones estilísticas (discursiva $o$ informativa, expresiva o confesional, apelativa o directiva); sus estratos metodológicos operacionales (fonológico, morfologico, sintáctico, semántico y simbólico; incluidas sus unidades -fonema, morfema, monema, sintagma, semema, mitema- , más sus relaciones, axiomas y reglas de funcionamiento); sus asociaciones o conciencias analíticas (simbólica, paradigmática, sintagmática); $y$, en definitiva, su insercion inevitable en todas las áreas del conocimiento humano, aunque más no sea como 
mero continente de los intinitos contenidos mentales.

La lingüística, ciencia del lenguaje por antonomasia, le dedico específicamente sus mejores preocupaciones, pero fue, a la vez, responsable de una desconcertante paradoja: por un lado, al desvincularse metodologicamente de las ciencias con las que venía asociada desde los albores de la civilización occidental, quedó convertida en ciencia autónoma; y por el otro, al mantener nítidas ciertas relaciones con las demás, pudo proyectarse hacia insospechadas direcciones. Así, sus vínculos con las ciencias naturales (fisiología, física) explican la complexión del lenguaje y el comportamiento de los sonidos; los establecidos con las ciencias puras (matemática, lógica, semiótica) esclarecen la actividad verbal y posibilitan una más convincente teoría del signo lingüístico; $y$, por último, los habidos con las otras ciencias del hombre (filosofTa, psicología, sociología, etnografía, antropología, historia de la cultura) le son átiles para interpretar el pensamiento idiomático, el simbolismo de la comunicación verbal, la estratificación dialectal de una comunidad, inclusive los métodos de observación y registro empleados durante la investigación científica. Ejemplos muy conocidos de esta interrelación disciplinaria los constituyen la geografia lingưística, la psicolingüística, la sociolingüística, la antropologTa estructural y hasta la última etnologTa 'emic-etic'.

La lingüística estructural -en especial, la fonológica de Praga y la glosemática de Copenhague, devenidas de las ideas de Baudouin de Courtnay y Ferdinand de Saussure- intento justamente obviar tales conexiones y someter el objeto y el método de los sistemas lingüisticos a sus propias reglas de juego. N. S. Trubetzkoy, el gran maestro de la escuela checa, lo confirma: "El fonema no puede ser definido satisfactoriamente ni por su naturaleza psicológica ni tampoco por su relación con las variantes fonéticas, sino única y exclusivamente por su función en la lengua. (...) Toda modificación que se introduzca en ella conduciría únicamente a una complicación que puede ser evitada" (2). Por su lado, L. Hjelmslev, el conductor de la escuela danesa, también lo corrobora: "La lingǘrstica ha de esforzarse por comprender el lenguaje no como un conglomerado de fenómenos no lingüísticos (físicos, fisiológicos, psicológicos, Iógicos, sociológicos) sino como una totalidad autosuficiente, como una estructura sui generis. Sólo de este modo puede el lenguaje por sí mismo someterse a tratamiento científico, sin que de nuevo queden defraudados quienes lo estudian, y pierdan la perspectiva. (...) Lo que se necesita es construir una teoria lingüística que descubra y enuncie las premisas de tal lingüística, que establezca sus métodos e indique el camino" (3). Y, 
en veruaa, yue el mismo asumio la insoilta tarea de esbozal los prolegómenos para dicha teoría y de inscribir a su glosemática en una ciencia semiótica que se despliega en un sistema paradigmático (lengua), mediante un proceso sintagmático (texto), verificados en el plano del contenido (pleremática) y en el plano de la expresión (cenemática).

No son la checa y la danesa las unicas escuelas que propusieron una nueva lingüistica descriptiva, estructural, sincrōnica, funcional. En Estados Unidos de Norteamérica surgieron las teorías de los 'constituyentes inmediatos', de la 'tagmémica' y de la 'generativa', las que, muy lejos de identificarse con aquellas, fundaron sus propios modelos de análisis y posibilitaron, simultáneamente, el avance espectacular de una ciencia que se habTa mantenido muy rezagada hasta principios de este siglo. No debe sorprender entonces que, a tan inusitado encumbramiento, haya seguido una retahíla de críticas, formuladas en todos los tonos posibles.

\section{4}

Sigamos nuestra exposición con la poesía. Desde Aristóteles hasta los formalistas rusos contemporáneos, la poesía ha sido tratada según criterios muy diversos entre sí, aunque ninguno le retacea su significado más profundo -el de 'creación' o 'composición' artística mediante la palabra-, ni la importancia preferencial de que siempre disfrutó en el espacioso y abigarrado mundo de las artes. El mejor testimonio de tan grande importancia aparece exhibido por el simple hecho de que la poética, habitáculo natural de la poesía, gozara, no necesariamente en todas las épocas por igual, del triple carácter -'artístico', 'técnico' y 'científico'-, el mismo que hubo de signar el sentido de prestigio cultural en la civilización de occidente.

Asimismo, esta poética a que aludimos no fue ortodoxamente interpretada a través del tiempo: la más celebre -la de Aristóteles - no era más que una teoría relativa a determinados tipos de discursos literarios -principalmente 'epopeya', 'tragedia' y 'comedia'- ; muchas de las que la siguieron no pasaron de huera colección de reglas o preceptos estéticos, prescriptos con exclusividad para la poesía -elegancias del lenguaje; tropos; figuras lógicas, descriptivas y patéticas; gêneros $y$ especies literarios; tonos y estilos; cualidades positivas y negativas; ritmo, rima, metro, combinación estrófica- ; etc.; y la última poética de vanguardia, la formalista, impuso una teoría de la estructura y del funcionamiento del discurso litera- 
rio mismo. estructura mucno mas general, de la que toda obra literaria no es más que una de sus posibles realizaciones, al margen de causas psicosociológicas o histórico-geográficas incidentes $y$, sobremanera, de la historia personal del autor.

Uno de los exponentes mayores de la poetica estructural, el genial Tzvetan Todorov, puntualiza los aspectos por tener en cuenta para el análisis del discurso, entendido éste como toda forma literaria posible: a) los registros del habla, constituidos por varios tipos de discurso; b) las visiones en el relato, o sea, la manera en que los acontecimientos relatados son percibidos por el narrador $y$, en consecuencia, por el lector virtual; c) las estructuras del texto, establecidas sobre la base de los tipos de relación existente entre las unidades minimas en que aquel se descompone; c) la sintaxis narrativa que presupone un sistema de segmentos lingüísticos; y d) la verosimilitud, conceptuada como opinión general, como una categoría que trasciende la oposición 'pasado/presente', instaurada por la instancia del discurso (4).

A simple vista, hasta el menos avisado se percata de la desemejanza habida entre el análisis estructural de Todorov y cualquiera de los modelos lingǘsticos aludidos: es que la semejanza corre subterránea, en las capas profundas de una misma concepción formal, lineal, sintagmática y sincrónica para una mejor descripción del hecho literario. En este sentido, desde V. Propp hasta A. J. Greimas, el consenso mayoritario autorizaba la descripción de las estructuras como tarea previa al estudio de los procesos, cambios, incluso los orígenes del texto literario. Otro ruso, E. Meletinski, al comentar el método de Vladimir Propp, lo ratifica: "(...) en su búsqueda de la especificidad genérica del cuento maravilloso, examina antes que nada el relato y analiza el desarrollo cronológico $y$, por consiguiente, la sintagmática, a fin de esclarecer la significación de cada sintagma dentro de un determinado asunto. De ahí que su modelo estructural sea lineal" (5). AsI considerado, sólo faltaba la formulaciōn de un modelo que alcanzara las más altas cumbres de la especulación estructuralista para el análisis de la narrativa. A Greimas le correspondería el privilegio de proponer los modelos 'actancial' y 'de transformación' para la descripción del cuento (incluido el mito), expuestos con enunciados y nomenclaturas de neto corte linguísticoestructural y con notaciones casi algebraicas (6).

Por supuesto, esta moderna concepción poética no habría de pasar impune para la crítica implacable. 
Por último, el mito. Es cierto que ya dimos cuenta de sus distintas acepciones etimologicas, pero no lo es menos el hecho de que ninguna de ellas acierta en revelar su prístina esencia; así como las múltiples interpretaciones que intentaron explicarlo o justificarlo, siglos mediante, no concitaron jamás un juicio unánimemente aceptado. Lo de menos parece ser que, tanto para los pueblos primitivos y los civilizados del mundo antiguo (egipcios, griegos, romanos, por ejemplo), como para los salvajes $y$ no salvajes del mundo actual, "el mito - según la bella digresión de Malinowski- no es sólo una historia, sino una realidad vivida que no pertenece al orden de la ficción, como las novelas de nuestros días, sino que es una realidad viva, que se cree ocurrió antaño, en los tiempos originales, y que desde entonces continúa influyendo sobre el mundo y el destino de los hombres. (...) realidad primordial, superior, más importante, que condiciona la vida presente, el destino $y$ las actividades de la humanidad, y cuyo conocimiento proporciona al hombre la motivación de sus actos rituales o morales, y, al mismo tiempo, le da indicaciones para realizarlos" (7). P. Grimal va aún más lejos con sus apreciaciones: "(...) el mito no es ajeno a nuestro pensamiento cotidiano, e incluso no se opone de ningún modo, por su esencia, al pensamiento científico. El mito, igual que la ciencia, tiene la ambición de explicar el mundo, haciendo inteligibles sus fenómenos. (...) si el mito es error, ¿no lo son también las 'verdades' científicas, destinadas perpetuamente a ser superadas? El mito y las 'verdades' provisionales de la ciencia son sólo aproximaciones diferentes de la 'verdad', ese enigma del mundo que sigue estándonos cerrado, tras de tantos trabajos y descubrimientos" (8).

En la actualidad, la mitología ha dejado de ser una mera colección de mitos de todo tiempo y lugar, analizados, clasificados y difundidos de mil insospechadas maneras, para arrogarse la calidad de teoría científica, repartida entre simbolistas, funcionalistas y estructuralistas: los primeros toman directamente como objeto de análisis los relatos míticos y se abocan a la tarea de descifrarlos sobre la base de símbolos que les son familiares y al margen de todo contexto sociocultural; los segundos acusan de falaces a tales desciframientos mientras no se determine la función que desempeña un mito en el contexto social familiar particular en que se lo utiliza; y los terceros, sin excluir el contexto, integran los textos míticos y sus diversas variantes en sistemas simbólicos. 
El análisis estructural del mito -producto natural de la corriente estructuralista puesta en marcha por Claude LéviStrauss desde el anchuroso campo de la antropología- comienza por segmentar el relato o sintagma mítico en elementos minimos llamados 'mitemas' -a la manera de los 'fonemas', 'monemas', 'sememas' - ; continúa con la confrontación de los mitemas de las distintas variantes de un mismo mito, y el consiguiente establecimiento de los 'conjuntos paradigmáticos'; y concluye con el ordenamiento de sus elementos en secuencias o 'hileras' diacrónicas que deben ser leídas sincrónicamente (las columnas). "Todo mito, pues, -sintetiza Lévi-Straussposee una estructura como de múltiples hojas, que en el procedimiento de repetición y gracias a êl transparenta en la superficie. (...) Respecto de la 'lengua' por una parte, y del 'habla' por otra, su posición sería efectivamente análoga a la del cristal: objeto intermedio entre un agregado estadístico de moléculas y la estructura molecular misma" (9).

De hecho: el método estructuralista de Lévi-Strauss tampoco sobreviviría indemne de comentarios polémicos.

6

Hasta aquí, las consideraciones generales acerca del lenguaje, la poesía y el mito; en adelante, la revisión crítica de ciertos aspectos comunes en el tratamiento metodológico a que los sometiera la corriente estructuralista contemporánea.

Partamos de esta afirmación de Jakobson: "La poética se ocupa de los problemas de estructura lingüística, de la misma forma en que la pintura se ocupa de las estructuras pict6ricas. Como la lingüística es la ciencia global de las estructuras lingüísticas, se puede considerar que la poética forma parte integral de la lingüística" (10). Si esto es así, con legítimo derecho puede argüirse que el relato mítico también forma parte de la lingüística, en virtud de su afinidad con el hecho poético y de su manifestación en estructuras lingüísticas. Pero, bien se sabe, serias objeciones dificultan la incondicional aceptación de aquella premisa, pese a las aparentes correspondencias e interrelaciones que se entraman, sobre todo, en el manejo de una misma terminología técnico-estructural: lengua/ habla, significante/significado, diacronía/sincronía, paradigma/ sintagma, fonema/morfema/semema/mitema/motifema. En principio, el parentesco simbólico "poesía/mito". favorecido por la opiniōn de personalidades ilustres, como Sigmund Freud, Otto Rank "Wilbur Marshall Lrban, queda desbaratado en el plano de la expresión lingüística por el fuicio de otro llustre, Lévi- 
Strauss: "(...) el lugar que el mito ocupa en la escala de los modos de expresión lingüística es el opuesto al de la poesía, pese a lo que haya podido decirse para aproximar uno a la otra. La poesía es una forma de lenguaje extremadamente difícil de traducir en una lengua extranjera, y toda traduccion entraña múltiples deformaciones. El valor del mito, por el contrario, persiste a despecho de la peor traducción. (...) La sustancia del mito no se encuentra en el estilo, ni en el modo de la narración, ni en la sintaxis, sino en la 'historia' relatada. El mito es lenguaje, pero lenguaje que opera en un nivel muy elevado" (11). Pues, otro tanto ocurre con la discutida terminología estructural arriba mencionada, a la que dedicamos párrafos aparte.

Cuando Saussure separó la lengua del habla, separaba a la vez: "10, lo que es social de lo que es individual; $2^{2}$, lo que es esencial de lo que es necesario y más o menos accidental" en el complejo fenómeno del lenguaje; simultáneamente deslindaba la 'língüística de la lengua' de la 'lingüística del habla'. No sospecho, entonces, que tal separación traería aparejada la renovación de teorías decadentes, pero, también opiniones desencontradas: por ejemplo, podría entenderse que el relato mítico, como producto social, como 'conciencia colectiva', estaría inscripto en el área de la lengua, y la poesía, como acto estético individual, en la infinitud del habla. Sin embargo, Charles Bally, al afirmar que "la estilística (ilingüística del habla?) abarca el dominio entero del lenguaje; todos los fenómenos lingüísticos, desde los sonidos hasta las combinaciones sintácticas más complejas", estaría nuevamente borrando las fronteras entre ambas lingüísticas saussureanas, $e$ incluyendo la poesía (¿y el mito?) en el ámbito de la lengua: al fin de cuentas, Jakobson parece no estar del todo equivocado.

Con respecto a la dicotomía significante/significado, Saussure reconoce el signo lingüístico como la amalgama de un concepto y una imagen acústica; L. Hjelmslev lo concibe como la conjunción de una forma pura del contenido con una forma pura de la expresión; y $D$. Alonso, sin contrariar esas mismas concepciones, llama "forma exterior" a la relación entre significante y significado, en la perspectiva desde el primero hacia el segundo, y "forma interior", a la misma relación, pero en la perspectiva inversa: ccorrespondería el mito a la "forma interior" y la poesía, a la "forma exterior"? Esta pregunta podría quedar satisfecha si ampliăramos un poco más el tema de los distintos tipos de relaciōn entre 'significado/significante'.

$$
\text { Roland Barthes concibe tres relaciones en todo signo: }
$$


"En primer lugar, una relación interior, la que une su significante con su significado (simbólica); luego, dos relaciones exteriores: la primera es virtual, une el signo a una reserva específica de otros signos, de donde se lo separa para insertarlo en el discurso (paradigmática); la segunda es actual, une el signo con otros signos del enunciado que lo preceden o que lo suceden (sintagmática)". En base a tales relaciones, Barthes habla de tres conciencias semiológicas del analista (no del sujeto hablante) y de tres tipos de imaginación del signo: profunda o simbólica, formal o paradigmática y funcional o sintagmática; e inscribe el relato mítico en la segunda, junto a los relatos oníricos y las obras muy temáticas; y la poesía, en la tercera, junto al teatro épico y las composiciones estructurales (12).

En cuanto a los ejes metodológicos para el análisis científico, el sincrónico y el diacrónico, respetan los estructuralistas, aunque no todos por igual, las nociones originales del maestro ginebrino: todo hecho de lengua, poético o mítico, debe estudiarse primero sincrónicamente, esto es, previendo las relaciones de elementos coexistentes, simultáneos; después diacrónicamente, esto es, siguiendo el transcurso de las sucesiones, cambios, transformaciones de esos mismos elementos a través del tiempo. En este sentido, los mayores errores cometidos por la lingüística, la poética $y$, al parecer, la mitología fueron: a) el haber confundido o superpuesto ambos ejes; y b) el no haber respetado la prelación necesaria del método sincrónico, con respecto del diacrónico.

Aún queda por tratar el problema de la estratificación del hecho lingüuístico $\mathrm{y}$, en consecuencia, del poético y mítico. Hoy, los linguistas no vacilan al determinar tres estratos: el fonológico, el morfológico y el sintáctico; los cuales, como sistemas que son, se conforman de unidades mínimas (fonema, morfema, sintagma lexical), de segmentos máximos (sílaba, palabra, sintagma oracional), de sus variantes (alofonos, alomorfos, o frases endocéntricas y exocéntricas), y de un cámulo de reglas de funcionamiento. Toda esta inmensa teoría no fue óbice para que semiólogos y antropólogos añadieran dos estratos más: el semántico y el simbólico, los que, por ser objetos de investigaciones recientes, se van convirtiendo, paso a paso, en sistemas con sus respectivas unidades (isememas?, ¿mitemas?, ¿motifemas?), variantes y transformaciones, más un tráfago de hipótesis y axiomas, todavía en apasionada discusión. Es indudable que poesía y mito pueden recorrer los peldaños de la estratificación aludida, pero no lo es menos el hecho de que se desenvuelvan mejor en los campos semántico y simbólico; porque 
el uno denota cosas, acontecimientos, relaciones, sensaciones, personas, personalidades, etc., y el otro connota atributos, sentimientos, imágenes, estados de ánimo, etc. Quiérase o no, poesía y mito continúan fraternalmente emparentados, sin que por ello tengan que identificarse.

Quizás la responsable de tales controvertidas identificaciones sea la excesiva y acelerada modernidad de la lingüística, disciplina piloto de las actuales ciencias humanas: el frenesí estructuralista se encargó de desatar una moda o esnobismo que terminó por contaminarlo todo; a tal punto que hubo necesidad de desbrozar el terreno para poner de relieve las confusiones producidas por el uso inadecuado de modelos y términos lingüísticos en otros ámbitos científicos. Georges Mounin lo denuncia implacable: "(...) los filósofos que acabamos de nombrar -Maurice Merleau-Ponty, Henri Lefebvre, Michel Foucault, Jac ques Lacan, entre otros- , espíritus todos ellos notables, brillantes, ricos, sólidos incluso, tienen como característica común el haber descubierto la linguística un poco tarde, haberla asimilado con cierta precipitación. El uso que hacen de las nociones que toman de esta lingüística es a menudo discutible, muchas veces erróneo. La manera según la cual uno de ellos se ha servido de tal o cual concepto lingüístico, merecería ya un largo análisis histórico y sobre todo crítico" (13).

Pese a la controversia, un criterio amplio termina por reconocer que la corriente estructuralista significó una conquista cultural necesaria, renovadora y estimulante. Ya Antonio Prieto lo declaró con el peso de su autoridad: "Pero la cosa no es tan grave e, históricamente, era de prever, porque las leyes de las mareas no se han modificado desde que la primera ola acarició una playa para luego retirarse. En cierto modo se ha producido una contramarea de reacción al viejo sistema del comentario de textos procedente de la lingüística (con Bally y su asepsia literaria), que queriendo fijarse sólo y nada más que en el texto, perdía el sentido literario en una retórica gramaticalización" (14). De acuerdo; siempre y cuando se rechacen las ínfulas estructuralistas de autosuficiencia e infalibilidad.

\section{7}

Pues bien; aquí queríamos llegar por una parte, reconocer la eficacia del método estructuralısta en el análisis de determinados aspectos del lenguaje, la poesía \ el mito; I por la otra, a despecho de esa misma eficacia, rendirnos ante las naturales divergencias que, justamente. separan al lenguaje, la poesía $\vee$ el mito. Algunas de ellas tueron apuntadas en el trans- 
curso de estas páginas; otras pueden nuclearse en torno de una sola cuestión, que puede ser ésta: a) el análisis de la lengua siempre pareció reservado a los sistemas fonolठgico, morfologico y sintáctico; b) el análisis poético y mítico, a los sistemas semántico y simbólico; pero c) el análisis esencial del mito escapa de los límites formales de la estratificación habitual entre los estructuralistas, para alcanzar insospechadas alturas filosóficas. Por más que la filosofía haya metido sus uñas en todas partes, nunca escarbó como en las entrañas del mito: la lógica, como ciencia del acto de la razón, del raciocinio, prescribió las leyes del pensamiento y del lenguaje; la estética, a horcajadas de la ontología y de la filosofía del arte, estipuló las leyes del arte $y$, por consiguiente, de la poesía; pero lógica y estética, sumadas a todas las otras ciencias filosóficas (cosmología, psicología, antropología, gnoseología, teología, ética, filosofía de la religión y de la cultura, etc.), intentaron desentrañar el grande misterio del mito, inclusive imponerle sus leyes. Por eso, el método estructuralista, que apenas pudo soportar el análisis formal o funcional del lenguaje y la poesía, resulta más que insuficiente para develar el complejísimo fenómeno mítico: podră describir su corteza, pero nunca descubrir esencialmente, íntegramente, su meollo.

Pero, la verdad es que lenguaje, poesía y mito viven y conviven -imenos mal!- en el espíritu de los hombres; para que haya entendimiento entre ellos; para ennoblecer la vida, para que se sepa de dónde se viene y a dónde se va. 
(1) Cfr. B. Malinowski, Estudios de psicología primitiva. El complejo de Edipo, trad. esp., Bs. As., Paidós, 1958, p. 40. Allí mismo distingue el mito de la leyenda y del cuento popular.

(2) Vid. N. S. Trubetskoy, Principios de fonología, trad. esp., Madrid, Cincel, 1973, p. 38 .

(3) Cfr. L. Hjelmslev, Prolegómenos a una teoría del lenguaje, trad. esp., Madrid, Gredos, 1971, pp. 14-15.

(4) Para esta reseña muy somera nos valimos de T. Todorov, "Poética", en DUCROT, SAFOUAN, WAHL, y otros, ¿Qué es el estructuralismo?, trad. esp., Bs. As., Losada, 1971.

(5) Vid. E. Meletinski, Estudio estructural y tipológico del cuento, trad. esp., Bs. As., Rodolfo Alonso Editor, 1972, p. 36.

(6) Cfr. A. J. Greimas, Semántica estructural. Investigación metodológica, trad. esp., Madrid, Gredos, 1973, pp. 236238, principalmente. Además, J. Courtes, Introducción a la semiótica narrativa y discursiva. Metodología y aplicación, trad. esp., Bs. As., Hachette, 1980.

(7) Vid. B. Malinowski, Mith in Primitive Psychology, Londres, 1926, pp. 21 y s.

(8) Vid. P. Grimal, "El hombre y el mito", en Mitologías, del Mediterráneo al Ganges, trad. esp., París-Buenos Aires, Larousse, 196, T. 1, pp. 4-5.

(9) Cfr. C. Levi-Strauss, Antropología estructural, trad. esp., Bs. As., EUDEBA, 1984, pp. 209-210. Véase, además, del mismo autor, Lo crudo y lo cocido, trad. esp., México, F.C.E., 1964, pp. 301 y s.

(10) Cfr. R. Jakobson, "Lingüística y poétıca", en El lenguaje y los problemas del conocimiento, colaboradores varios, 
trad. esp., Bs. As., Rodolfo Alonso Editor, 1971, p. 9.

(11) Vid. C. Levi-Strauss, Antropología estructural, ya citada, p. 190.

(12) Cfr. R. Barthes, "La imaginación del signo", en El lenguaje y los problemas del conocimiento, colaboradores varios, ya citada, p. 127.

(13) Cfr. G. Mounin, Claves para la lingüística, trad. esp. Barcelona, Anagrama, 1969, pp. 9 y s.

(14) Cfr. A. Prieto, Ensayo semiológico de sistemas literarios, Barcelona, Planeta, 1972, pp. 16 y s. 